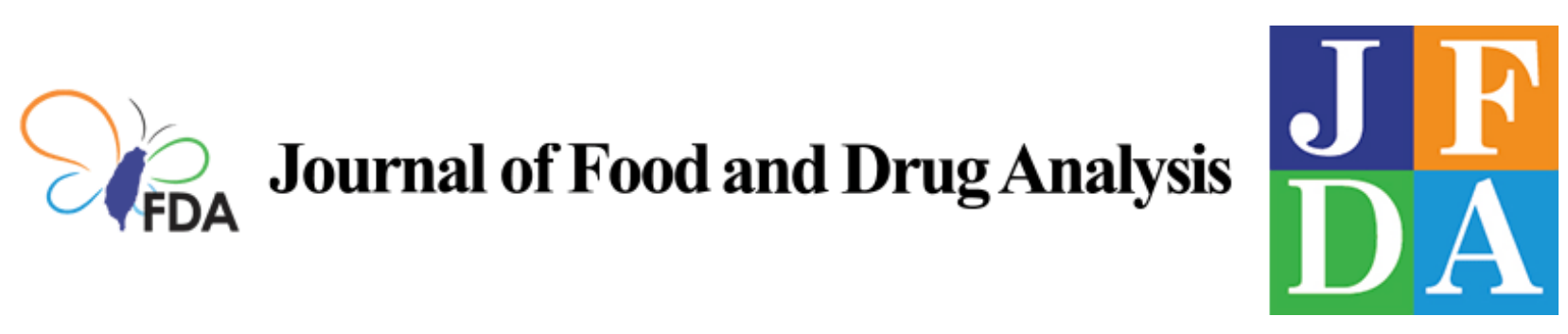

Volume 29 | Issue 1

Article 1

2021

\title{
Suitability of Sugar Alcohols as Antidiabetic Supplements: A Review
}

Follow this and additional works at: https://www.jfda-online.com/journal

Part of the Food Science Commons, Pharmacology Commons, and the Toxicology Commons (c) (i)(9)

This work is licensed under a Creative Commons Attribution-Noncommercial-No Derivative Works 4.0 License.

\section{Recommended Citation}

Msomi, Nontokozo Z.; Erukainure, Ochuko L.; and Islam, Md. Shahidul (2021) "Suitability of Sugar Alcohols as Antidiabetic Supplements: A Review," Journal of Food and Drug Analysis: Vol. 29 : Iss. 1 , Article 1. Available at: https://doi.org/10.38212/2224-6614.3107

This Review Article is brought to you for free and open access by Journal of Food and Drug Analysis. It has been accepted for inclusion in Journal of Food and Drug Analysis by an authorized editor of Journal of Food and Drug Analysis. 


\section{Suitability of Sugar Alcohols as Antidiabetic Supplements: A Review}

\section{Cover Page Footnote}

The authors would like to acknowledge the Research Office, University of KwaZulu-Natal and the National Research Foundation (NRF), Pretoria, South Africa (Grant number 1124300) for support. 


\title{
Suitability of sugar alcohols as antidiabetic supplements: A review
}

\author{
Nontokozo Z. Msomi ${ }^{a}$, Ochuko L. Erukainure ${ }^{b}$, Md. Shahidul Islam ${ }^{a, *}$ \\ a Department of Biochemistry, School of Life Sciences, University of KwaZulu-Natal, (Westville Campus), Durban 4000, South Africa \\ ${ }^{b}$ Department of Pharmacology, School of Clinical Medicine, Faculty of Health Sciences, University of the Free State, Bloemfontein 9300, \\ South Africa
}

\begin{abstract}
The major goals in the management of diabetes are to maintain optimum control of high blood glucose level or hyperglycemia. Dietary modification is one of the most recommended treatment modalities for diabetic patients. The use of foods sweetened with sugar alcohols (also known as polyols) such as xylitol, sorbitol, mannitol, maltitol, lactitol, isomalt and erythritol has brought an escalating interest in the recent years since some sugar alcohols do not rise plasma glucose, as they are partially digested and metabolised. Diet composition and adequacy may be altered by replacing carbohydrates with sugar alcohols. It has been established that these polyols are appropriate sugar substitutes for a healthy lifestyle and diabetic foods. The present review focuses on the evidence supporting the use of sugar alcohols in the management of diabetes, by evaluating their physical and chemical properties, metabolism, absorption, glycemic and insulinemic responses. Although documentation on the glycaemic and insulinemic response of polyols is evident that these compounds have beneficial effects on the better management of hyperglycemia, the possible side effects associated with their normal or higher dosages warned their use according to the relevant Food \& Drug Administration guidelines. For the same reason, future studies should also focus on the possible toxicity and side effects associated with the consumption of sugar alcohols in order to define their safety.
\end{abstract}

Keywords: Diabetes, Glycemic index, Insulinemic index, Sugar alcohols, Sweeteners

\section{Introduction}

$\mathrm{T}$ he global prevalence of diabetes is increasing progressively, with an estimated 463 million people living with diabetes and a projection of 700 million by 2045 , the vast majority of whom have type 2 diabetes (T2D) [1]. Epidemic of diabetes has astounding healthcare expenditure and significant impacts in the quality of life [2]. In 2019, the global diabetes-related healthcare expenditure reached an estimated 760 billion USD, with a $14.5 \%$ increase from 2017 [1].

Diabetes is a multifactorial disease and one of its most prominent association is the consumption of excess refined sugar or sugar containing foods and food products [3,4]. Therefore, the World Health Organization issued nutritional guidelines not only to reduce the consumption of added sugars but also to reduce the daily energy intake from refined sugar [5]. This has led to the identification of modifiable diets and lifestyle factors for the prevention and better management of diabetes [6,7]. A growing interest in products sweetened with sugar alcohols in the market has transpired, targeted towards people with diabetes $[8,9]$. Studies have suggested that sugar alcohols have the ability to alter the nutritional adequacy of a diet since they have lower energy values due to the way they are metabolized [10]. Therefore, these sugar substitutes are useful in the maintenance of a nutritionally balanced diet for diabetic individuals [11]. Considering all above, the present review was designed to analyse the beneficial effects, mechanisms of actions and possible side effects of different widely used sugar alcohols for the better and safer management of hyperglycemia and diabetes.

Received 26 July 2020; revised 2 November 2020; accepted 12 January 2021.

Available online 15 March 2021

* Corresponding author at: Department of Biochemistry, University of KwaZulu-Natal, Westville Campus, Durban 4000, South Africa.

E-mail address: islamd@ukzn.ac.za (Md.S. Islam). 


\section{Sugar alcohols}

Sugar alcohols (polyols) are chemically defined as saccharide derivatives in which a ketone or aldehyde group is replaced by a hydroxyl group $[9,12]$. They are mostly known as caloric/nutritive sweeteners that are white and water-soluble solids which are naturally present in small amounts in some fruits and vegetables and are commercially produced by hydrogenation reaction $[8,13,14]$. Sugar alcohols are extensively used in sugar-free foods and food products such as gum, fruit spread, candy, baked goods and ice cream [15]. They are used as sugar substitutes in diabetic food formulations to reduce water activity in 'intermediate moisture foods'; improvement of dehydrated foods; as softeners; and as crystallization inhibitors [16]. Some sugar alcohols are also widely used in oral and dental care products due to their proven and relevant beneficial effects $[17,18]$.

\subsection{Classification of sugar alcohols}

Sugar alcohols (Fig. 1) are classified into three groups according to the number of saccharide units present in the molecule as follows: (i) Monosaccharide-derived sugar alcohols: for examplexylitol, sorbitol and mannitol. These monosaccharides are derived from xylose, glucose and mannose respectively; (ii) Disaccharide-derived sugar alcohols: this includes lactitol and maltitol which are derived by the hydrogenation of lactose and maltose, respectively. (iii) Polysaccharidederived sugar alcohols mixture: this includes Isomalt which is a 1:1 mixture of alpha-D-glucopyranosyl-[1-6]-D-sorbitol (GPS) and alpha-Dglucopyranosyl-[1-6]-D-mannitol (GPM) [8,9,15].

\subsubsection{Xylitol}

Xylitol is a five-carbon crystalline substance occurring naturally in small amounts in many plants, micro-organisms and animal tissues $[19,20]$. It is produced in humans as part of the hepatic metabolism of carbohydrates at levels of approximately 5-15 g per day [21]. It is also commercially produced by the hydrogenation of xylose using a nickel-catalyzed reaction process [22]. The molecule contains a tridentate ligand $(\mathrm{H}-\mathrm{C}-\mathrm{OH})_{3}$ which reacts with numerous polyvalent cations and oxyacids [13]. Xylitol is roughly as sweet as sucrose but with moderately lower caloric value of $(2.4 \mathrm{kcal} / \mathrm{g})$ compared to sucrose $(4 \mathrm{kcal} / \mathrm{g})$, hence it is widely used in foods and pharmaceutical products [20].

\subsubsection{Sorbitol}

Sorbitol is a six-carbon alditol also known as Dglucitol. It is naturally present in fruits (peaches, apples, cherries, apricots, nectarines and pears) and some vegetables $[23,24]$. It is produced from glucose by catalytic hydrogenation with hydrogen gas and nickel catalyst at high temperatures [25,26]. In alkaline conditions it is produced by electrochemical reduction of dextrose [23]. Sorbitol has sweetness of about $60 \%$ of sucrose, with fewer calories $[9,27]$. It also characterizes with a 20 -fold higher solubility in water than mannitol $[28,29]$. Sorbitol has non-cariogenic properties therefore it is used for nutritional purposes in products designated for diabetic people [30].

\subsubsection{Mannitol}

Mannitol is six-carbon polyol, an optical isomer of sorbitol which is used as a reserve carbohydrate by some fungi, bacteria and seaweeds [31,32]. It is also naturally found in high amounts in olives, carrots, figs, pineapples, sweet potatoes and larches [29,33-35]. Industrial production of mannitol is based on the catalytic hydrogenation of glucose/ fructose derived from invert starch or sugar at high temperatures and pressure $[33,36]$. It has a caloric value of $1.6 \mathrm{kcal} / \mathrm{g}$ which is $50 \%$ sweet as compared to table sugar, with a desirable cooling effect that is efficient in masking bitter tastes [37]. This sugar alcohol is non-hygroscopic [35], which is used as a bulking agent in sugar free coatings and a dusting powder for chewing gum [9]. Mannitol is not metabolized by humans therefore it doesn't induce hyperglycemia with no insulinemic and glycemic indexes [38].

\subsubsection{Maltitol}

Maltitol is a disaccharide polyol (4-O- $\alpha$-D-glucopyranosyl-D-glucitol), formed from the hydrogenation of maltose to produce an $\alpha-1,4$ glucose-sorbitol linked polyol $[9,39,40]$. It is a crystalline powder that acts as a bulking agent, a stabilizer, an emulsifier, thickener and sweetener [9]. Maltitol properties such as sweetness and taste resemble that of sucrose [34]. Maltitol is a non-cariogenic agent with applications in many sugar-free foods, as well as numerous reduced-calorie and reduce-fat foods $[26,40]$.

\subsubsection{Lactitol}

Lactitol is disaccharide sugar alcohol obtained from the hydrogenation of lactose using nickel as a catalyst. Its production is composed of galactose and 
sorbitol [41-43]. Lactitol is an odourless white crystalline powder with a sweetness that is $30-40 \%$ of sucrose $[15,41]$. It has an anhydrous form which is applicable in case of moisture-sensitive products. It is used as an emulsifier, thickener and sweetener [9].

\subsubsection{Isomalt}

Isomalt is a mixture of two isomeric disaccharide alcohols: gluco-sorbitol ( $\alpha$-D-gluco-pyranosyl-1-6-
Sorbitol) and gluco-mannitol ( $\alpha$-D-gluco-pyranosyl1-6-mannitol) [25]. It is produced from sucrose in a two-step process, which makes isomalt chemically and enzymatically more stable than sucrose [44,45]. Isomalt on average has $45-65 \%$ of the sweetness of sucrose. It has synergistic effects when combined with other sugar alcohols or with high-intensity sweeteners, it is also anti-cariogenic and does not increase blood glucose or insulin levels $[9,30]$. This
Xylitol<smiles>OC[C@@H](O)C(O)[C@H](O)CO</smiles>

Mannitol<smiles>OC[C@@H](O)[C@@H](O)[C@H](O)[C@H](O)CO</smiles>

Sorbitol<smiles>OC[C@@H](O)[C@@H](O)[C@H](O)[C@H](O)CO</smiles>

Erythritol<smiles>OC[C@H](O)[C@H](O)CO</smiles>

Isomalt<smiles>OC[C@H](O)[C@@H](O)[C@H](O)CO[C@H]1O[C@H](CO)[C@@H](O)[C@H](O)[C@H]1O</smiles>

Maltitol

Lactitol<smiles>OC[C@H]1O[C@@H](C[C@H]([C@@H](O)CO)[C@@H](O)[C@H](O)CO)[C@H](O)[C@@H](O)[C@@H]1O</smiles><smiles>OC[C@H](O)[C@@H](O[C@@H]1O[C@H](CO)[C@@H](O)[C@H](O)[C@H]1O)[C@H](O)[C@H](O)CO</smiles>

Fig. 1. Chemical structure of commonly used sugar alcohols. 
polyol is partially digested in the intestines, only supplying half the caloric value of sucrose $[39,45]$.

\subsubsection{Erythritol}

Erythritol is a four-carbon polyol, that occurs naturally and widely distributed in nature. It occurs as a storage or metabolite compound in fungi and seaweeds, and as a constituent of numerous fruits such as pears, melons and grapes [12,46]. It is also commercially produced using fermentation in processed vegetables, fermented foods and drinks [12]. It is a symmetrical molecule, therefore existing in one form, the meso form [13]. It forms anhydrous crystals with approximately $60-80 \%$ sweetness that of sucrose, with no caloric effect and good digestibility without impacting blood glucose and insulin levels $[47,48]$. Its other general features include high stability in acidic and alkaline environments, and high stability against heat [46].

\subsection{Physical and chemical properties}

The probability of a sugar alcohol to be used as a sweetener depends on its properties which include physical, chemical, processing and sensory (Table 1) [16]. These compounds have numerous common properties that are important in selecting the most suitable polyol for a food application, these include:

- Sweetness: Sweetness is an important property of any sugar alcohol or sugar alternative. The sweetness of sugar alcohols is measured relatively to the sweetness of sucrose or table sugar. The sweetness of sugar alcohols varies from half as sweet to equal of that of sucrose (Table 2) $[9,39]$.

- Cooling Effect (Heat of solution): Each sugar alcohol is characterized by negative heat of solution which is the energy requiring process to dissolve the crystals. Some polyols such as isomalt have a noticeable high heat in solution followed by a cooling effect in the mouth. Cooling effect together with sweetness are midst the most important properties of polyols in their use in pharmaceutical products with soothing effects, i.e., breath mints, cough drops and lozenges $[13,40,49]$.

- Solubility: The solubility of sugars and polyols in water is greatly affected by the extent of temperature. The solubility of the compounds increases with temperature. Some polyols such as xylitol are highly soluble in water. Others like mannitol are slightly but it does not confine their use in food applications [16].

- Hygroscopicity: Hygroscopicity is the tendency for materials to take up moisture from their surroundings or atmosphere. The hygroscopicity of food products has very serious significance during the production and storage of the food, and it may affect how the ingredient itself is stored. Polyols that are highly water-soluble also tend to be very hygroscopic. This behaviour may assist in adding and retaining moisture in food products $[16,25]$.

- Molecular weight: The molecular weight of polyols is important when replacing sugars with polyols, to ensure the colligative properties remain unaffected. It can impact the texture, viscosity, osmotic pressure, freezing properties and crystallization [40].

- Reducing power: Sugar alcohols have additional hydrogen atoms which can be deposited on other metabolites to produce chemically reduced products and intermediates of metabolism [19]. Reducing power of different sugar alcohols denote the level of their antioxidant activity $[50,51]$.

- Hydrophilicity: Sugar alcohols have a great number of hydroxyl groups making them readily soluble in saliva. Xylitol and erythritol are highly hydrophilic sugar alcohols which are able to compete with water molecules for the hydration layer of biomolecules [19].

- Absence of a reducing carbonyl group: This property makes the molecules less reactive chemically than the corresponding ketoses and aldoses. Therefore, some polyols avoid these chemical reactions that make many dietary hexose-based sugars acidogenic and cariogenic in human dental plaque [52].

Table 1. Chemical and physical characteristics of Sugar Alcohols [Adapted from Refs. [9,37,49].

\begin{tabular}{llllll}
\hline Sugar alcohol & Molecular weight & Melting point $\left({ }^{\circ} \mathrm{C}\right)$ & Heat of solution & Viscosity at $25{ }^{\circ} \mathrm{C}$ & Hygroscopicity \\
\hline Xylitol & 152.15 & 94 & -36 & Very low & Medium \\
Sorbitol & 182.17 & 97 & -26 & Medium & High \\
Mannitol & 182.172 & 165 & -29 & Low & Mow \\
Maltitol & 344.313 & 150 & -19 & Medium & Medium \\
Lactitol & 344.313 & 94 & -14 & Very low & Very low \\
Isomalt & 688.62 & 167 & -9 & High & Low \\
Erythritol & 122.12 & 121 & -43 & Very low & Very low \\
\hline
\end{tabular}


Table 2. Relative sweetness of sugar alcohols compared to sucrose [Adapted from Ref. [9]].

\begin{tabular}{ll}
\hline Sugar alcohol & Sweetness (Sucrose =1) \\
\hline Xylitol & 1.0 \\
Sorbitol & $0.5-0.7$ \\
Mannitol & $0.5-0.7$ \\
Maltitol & 0.9 \\
Lactitol & $0.3-0.4$ \\
Isomalt & $0.45-0.65$ \\
Erythritol & $0.6-0.8$ \\
\hline
\end{tabular}

- Free radical scavenging: Because of their polyol nature, some sugar alcohols, such a D-mannitol, xylitol and erythritol, have been investigated as potential sources of free radical scavenging activity in biological systems [13,53].

- Complexation: Sugar alcohols can form complex compounds (chelate-like structures), due to their polyoxy structure. Complexes with calcium iron are important in view of tooth mineralization. These complexes are not strong enough to play a part in tooth demineralization. However, the presence of sugar alcohols in the mouth is believed to enable remineralization of caries lesions [19].

\subsection{Physiological aspects}

\subsubsection{Digestion, absorption and metabolism of sugar alcohols}

Disaccharide-derived and polysaccharide-derived sugar alcohols are converted into their monosaccharide components after ingestion. Most of these monosaccharides are thereafter absorbed through passive diffusion in the small intestine [54]. Most of the sugar alcohols are partially absorbed from the human small intestine, approximately from $0 \%$ for lactitol to nearly $80 \%$ for sorbitol [8]. The unabsorbed sugar alcohols are metabolized indirectly through fermentative degradation by colonic bacteria producing short chain fatty acids [39,52]. These are absorbed, providing energy to the body. It has been shown that sugar alcohols are incompletely metabolised in humans, as they have been recovered in urine [8]. The partial absorption and incomplete metabolism of sugar alcohols suggests that they provide lesser amounts of energy compared to sucrose $[37,55]$.

\subsubsection{Caloric value}

Polyols are known to have lower nutritional values compared to sucrose (Table 3). The energy provided by each sugar alcohol differs because of their digestibility, absorption and metabolism $[9,37]$.
Table 3. Caloric values of sugar alcohols [Adapted from Refs. [35,47]].

\begin{tabular}{lllll}
\hline Sugar alcohols & \multicolumn{5}{l}{ Caloric value $(\mathrm{kcal} / \mathrm{g})$} \\
\cline { 2 - 5 } & Europe & Japan & America & Mean caloric value \\
\hline Xylitol & 2.4 & 3 & 2.4 & 2.6 \\
Sorbitol & 2.4 & 3 & 2.6 & 2.7 \\
Mannitol & 2.4 & 2 & 1.6 & 2 \\
Maltitol & 2.4 & 2 & 2.1 & 2.1 \\
Lactitol & 2.4 & 2 & 2 & 2.1 \\
Isomalt & 2.4 & 2 & 2 & 2.1 \\
Erythritol & 0 & 0 & 0 & 0 \\
Sucrose & 4 & 4 & 4 & 4 \\
\hline
\end{tabular}

The energy content varies according to different legislations (Table 3). In Europe, the caloric value of sugar alcohols is set at $2.4 \mathrm{kcal} / \mathrm{g}$ except for erythritol which has a value set at $0 \mathrm{kcal} / \mathrm{g}$ since it cannot be metabolized $[37,49]$. However, the legislations in Japan and America set the caloric value of polyols within the range of $0-3 \mathrm{kcal} / \mathrm{g}[9,39,49]$. The minute caloric value of polyols proposes in helping consumers to reduce their energy intake and to lose weight [39]. Details caloric values of different sugar alcohols as specified in different countries are presented in Table 3.

\subsubsection{Blood glucose and insulin response}

Polyols are considered to elicit low glycaemic and insulinemic responses due to the incomplete absorption into the blood stream from the small intestine (Table 4) $[13,53]$. They are also associated with lipogenesis inhibition as well as lower insulin production. These properties make polyols popular sweeteners among diabetics and people on low carbohydrate diets $[9,56]$. The detail effects of sugar alcohols on diabetics are presented in Table 5 .

\subsection{Studies on antidiabetic properties of sugar alcohols}

\subsubsection{Xylitol}

The consumption of xylitol is accepted for diabetes to help in the management of hyperglycemia as its metabolism is in dependant of insulin $[9,49]$. Numerous studies have been undertaken to

Table 4. Glycaemic and insulinemic indexes of Sugar Alcohols [Adapted from Refs. [38,49,53]].

\begin{tabular}{lll}
\hline Sugar alcohol & Glycaemic index & Insulinemic index \\
\hline Xylitol & 13 & 11 \\
Sorbitol & 9 & 11 \\
Mannitol & 0 & 0 \\
Maltitol & 35 & 27 \\
Lactitol & 6 & 4 \\
Isomalt & 9 & 6 \\
Erythritol & 0 & 2 \\
Sucrose & 69 & 48 \\
\hline
\end{tabular}




\begin{tabular}{|c|c|c|c|c|}
\hline Disease model & Treatment & Duration & Mechanisms of action & References \\
\hline Type 2 diabetic rats & $10 \%$ xylitol solution (Ad libitum) & 4 weeks & $\begin{array}{l}\text { - Diabetic parameters including pancreatic } \\
\text { morphology and serum lipids improved } \\
\text { - Reduction of blood glucose and serum fructosamine }\end{array}$ & [58] \\
\hline Non-diabetic and type 2 diabetic rats & $\begin{array}{l}\text { 164.31-2628.99 mM xylitol in vitro. } \\
657.25-2628.99 \mathrm{mM} \text { xylitol ex vivo. } \\
\text { Xylitol }(1 \mathrm{~g} / \mathrm{kg} \mathrm{bw})\end{array}$ & $\begin{array}{l}2 \mathrm{~h} \\
\text { Single oral dose }\end{array}$ & $\begin{array}{l}\text { - Inhibited } \alpha \text {-amylase and } \alpha \text {-glucosidase } \\
\text { activities and jejunal glucose absorption. } \\
\text { - Improved muscle glucose uptake } \\
\text { - Delayed gastric emptying } \\
\text { - Reduced blood glucose level }\end{array}$ & [59] \\
\hline Non-obese healthy men & $25 \mathrm{~g}$ of xylitol & Single oral dose & $\begin{array}{l}\text { Lower plasma glucose and insulin } \\
\text { response compared to glucose }\end{array}$ & [65] \\
\hline Non-diabetic human subjects & 25 or $50 \mathrm{~g}$ of sorbitol & Single oral dose & - Did not significantly elevate glucose levels & [70] \\
\hline No-diabetic and type 2 diabetic rats & $\begin{array}{l}2.5-20 \% \text { sorbitol ex vivo. } \\
\text { Sorbitol }(0.4 \mathrm{~g} / \mathrm{kg} \mathrm{bw})\end{array}$ & $\begin{array}{l}2 \mathrm{~h} \\
\text { Single oral dose }\end{array}$ & $\begin{array}{l}\text { - Inhibited jejunal glucose absorption. } \\
\text { - Increased muscle glucose uptake } \\
\text { - Delayed gastric emptying } \\
\text { - Reduced blood glucose level }\end{array}$ & [73] \\
\hline Non-diabetic rats & Diet containing $20 \%$ mannitol & 8 weeks & $\begin{array}{l}\text { - Normal glucose metabolism } \\
\text { - Lower serum insulin response and } \\
\text { cholesterol concentrations }\end{array}$ & [74] \\
\hline Non-diabetic human subjects & $50 \mathrm{~g}$ of maltitol & Single oral dose & $\begin{array}{l}\text { - Lower plasma glucose and insulin } \\
\text { response compared to sucrose }\end{array}$ & [77] \\
\hline Non-diabetic and type 2 diabetic human subjects & 30 or $50 \mathrm{~g}$ of maltitol & & $\begin{array}{l}\text { - Lower plasma glucose and insulin } \\
\text { response compared to sucrose }\end{array}$ & [78] \\
\hline Non-obese healthy men & $25 \mathrm{~g}$ of lactitol & Single oral dose & $\begin{array}{l}\text { - Rise in plasma glucose, insulin and } \\
\text { C-peptide concentrations were } \\
\text { lower compared to glucose }\end{array}$ & [65] \\
\hline Non-diabetic healthy human subjects & $30 \mathrm{~g}$ of isomalt (Daily) & 4 weeks & $\begin{array}{l}\text { - Lower postprandial plasma glucose } \\
\text { and reduced fructosamine } \\
\text { compared to sucrose }\end{array}$ & [44] \\
\hline Non-diabetic and type 2 diabetic rats & $\begin{array}{l}2.5-20 \% \text { erythritol ex vivo. } \\
\text { Erythritol }(1 \mathrm{~g} / \mathrm{kg} \mathrm{bw})\end{array}$ & $\begin{array}{l}2 \mathrm{~h} \\
\text { Single oral dose }\end{array}$ & $\begin{array}{l}\text { - Increased muscle glucose uptake } \\
\text { - Reduced intestinal } \\
\text { glucose absorption and } \\
\text { gastric emptying }\end{array}$ & [85] \\
\hline Type 2 diabetic rats & 100,200 or $400 \mathrm{mg}$ of erythritol (Daily) & 10 days & $\begin{array}{l}\text { - Decreased serum glucose } \\
\text { levels compared to control } \\
\text { - Reduction of thio-barbituric } \\
\text { acid reactive substances, creatinine } \\
\text { and 5-hydroxymethylfurfural compared to control }\end{array}$ & [92] \\
\hline
\end{tabular}


examine the effects of xylitol on blood glucose and insulin levels for inclusion in diabetic foods. Mushtaq et al. [22] reported the ability of xylitol (extracted from mung bean halls) as a supplement for three weeks to reduce serum glucose in normal and diabetic rats with a reduction in food intake and weight gain in a dose dependent manner. Therefore, indicating its glycemic control effect [22]. The supplementation of $10 \%$ xylitol has demonstrated the ability to improve diabetes associated parameters including reduction in blood glucose and serum fructosamine levels, better glucose tolerance in diabetic rats $[57,58]$. A study by Chukwuma and Islam [59] examined the mechanisms behind the anti-diabetic effects of xylitol using numerous experimental models. It was reported that increasing concentrations of xylitol dose dependently inhibited $\alpha$-amylase and $\alpha$-glucosidase enzymes activity in vitro. Secondly, in ex vivo condition, xylitol dose-dependently decreased intestinal glucose absorption and increased muscle glucose uptake. Furthermore, a bolus dose of xylitol significantly delayed gastric emptying with increased intestinal transit time in non-diabetic and diabetic rats [59].

The supplementation of xylitol in rats receiving a high-fat diet has been shown to be beneficial in preventing obesity and metabolic abnormalities in a study conducted by Amo et al. [60]. It was observed that xylitol-fed rats compared to high fat diet fed rats had significantly lower visceral fat mass and plasma lipid concentrations, with an increase in lipogenic enzymes, fatty acid oxidation and ChREBP [60]. Xylitol consumption in type 2 diabetic rats has also been implicated in ameliorating oxidative stress, a factor associated with the exacerbation of diabetes [61].

In human studies, it has been observed that oral administration of xylitol causes small increase in blood glucose in healthy and diabetic patients [62-64]. Similarly, plasma insulin concentrations do not upsurge [62] or only moderately increase after the administration of xylitol [64]. Xylitol in comparison to glucose in healthy non-obese men after ingestion had significantly lower increases in plasma glucose and insulin concentrations [65]. These observations confirm that xylitol does not increase blood glucose to a significant extent. It has also been reported that xylitol has a good tolerance at doses ranging from 20 to $70 \mathrm{~g} /$ day [66]. A study by Foerster et al. [67] reported the good tolerance of xylitol in diabetic children with type 1 . The study was conducted for four weeks with each child receiving $30 \mathrm{~g} /$ day of xylitol [67]. The tolerance of xylitol was further observed at a higher dose of $70 \mathrm{~g} /$ day in type 1 , type 2 and healthy individuals over a period of six weeks [68]. The data from these investigations present that xylitol can be safely used as a sugar alternative in diabetic foods.

\subsubsection{Sorbitol}

The use of sorbitol as a sweetening agent in diabetic foods/diets has received substantial attention since its first recommendation for this purpose in 1929 [69]. In 1941 [70], Ellis and Krantz observed that a single dose of 25 or $50 \mathrm{~g}$ of sorbitol does not elevate blood glucose levels in normal individuals [70]. They further examined the oral administration of $50 \mathrm{~g}$ of sorbitol in mild and moderately severe diabetics reported that sorbitol did not significantly induce postprandial hyperglycemia [71]. A study by Kang et al. [72] investigated the inhibitory activity of sorbitol against rat intestinal $\alpha$-glucosidase and porcine pancreatic $\alpha$-amylase in vitro. It was reported that sorbitol possesses an inhibitory effect on these carbohydrate digesting enzymes [72]. These observations suggest the anti-hyperglycemic activity of sorbitol. Sorbitol has also shown its apparent glycemic control effects $e x$ vivo and in vivo. It was reported to inhibit glucose absorption in rat jejuna and increased glucose uptake in rat psoas muscle with or without insulin in a concentration dependant manner, ex vivo. In normoglycemic and type 2 diabetic rats, sorbitol delayed gastric emptying, enhanced digesta transit, inhibited intestinal glucose absorption and decreased blood glucose levels. Therefore, it was documented that sorbitol has a potential to be used as an anti-hyperglycemic sweetener in diabetic foods and food products [73].

\subsubsection{Mannitol}

Mannitol has glycemic and insulinemic indexes of 0 , thus it does not induce hyperglycemia which allows it to be consumed by diabetic individuals [33,39]. Mäkinen and Hamalainen [74] studied the effects of feeding high amounts of mannitol on rat metabolism. The animals were fed a diet that contained 20\% mannitol for 8 weeks. The animals presented normal glucose metabolism, associated with lower blood glucose levels and higher liver glycogen levels compared to the control animals. The animals also presented lower insulin secretion and lower serum cholesterol concentrations. Therefore, the metabolism of mannitol can be maintained within normal physiological limits [74]. A study by Dillard et al. [75] investigated the toxicity of alloxan in rats in relation to pentane and ethane produced during lipid peroxidation induced by i.p. injection of $20 \mathrm{mg}$ of alloxan/100 g b.w. Animals injected with $100 \mathrm{mg}$ 
of mannitol/100 g b.w (i.p) $30 \mathrm{~min}$ prior to alloxan were protected from the peroxidative effects of alloxan which was shown by the reduced production of pentane and ethane. The prevention in the formation of thiobarbituric reactants in plasma and liver of the animals additionally presented the protective effect of mannitol. Mannitol further reduced the plasma glucose in the animals after alloxan injection, presenting its hyperglycemic potential [75].

\subsubsection{Maltitol}

Maltitol is one of the most absorbed and metabolized disaccharide polyols. However, its glucose and insulin response after its consumption is lower as compared to sucrose [9]. A study conducted in vitro has shown that maltitol is able to exhibit significant inhibition of $\alpha$-glucosidase and $\alpha$-amylase activities [72]. Moreover, maltitol has been reported to inhibit glucose absorption in isolated rat jejunum and increased glucose uptake in isolated rat psoas muscle in the presence of insulin [76]. These observations suggest the use of maltitol for diabetic individuals by reducing carbohydrate digestion, absorption of glucose and postprandial hyperglycemia [72,76].

The available data on human studies suggest that maltitol is a good alternative sweetener to sucrose. A single dose of $50 \mathrm{~g}$ maltitol led to significantly lower glucose and insulin responses in healthy young subjects compared to sucrose [77]. A single oral dose of $30 \mathrm{~g}$ or $50 \mathrm{~g}$ maltitol in type 2 diabetic subjects also exhibited lower glucose and insulin responses compared to sucrose [78,79]. Additionally, a study by Quilez et al. [80] examined the consumption of low-calorie muffins containing maltitol compared to conventional plain muffins in non-diabetic healthy subjects. The subjects fed with maltitol showed improved blood glucose, insulin and lipidemic response in comparison to conventionally fed subjects [80].

\subsubsection{Lactitol}

The metabolism of lactitol is unique, once consumed it presents a negligible effect on blood glucose levels. It passes undigested to the colon, without being broken down by any enzymatic activity in the intestine. Henceforth, there is no condition for insulin rendering it appropriate for diabetic individuals $[9,49]$. Natah et al. [65] reported that after the ingestion of $25 \mathrm{~g}$ lactitol, the rise in plasma glucose, insulin and C-peptide concentrations were lower compared to ingestion of $25 \mathrm{~g}$ glucose in healthy non-obese men. It was suggested that lactitol is a suitable component in the diet for diabetic patients due to its lower glucose and insulin responses [65].

A study by Shimomura et al. [81] examined the effects of ingesting a $46 \mathrm{~g}$ non-sugar chocolate containing polydextrose and lactitol in place of sucrose and lactose on the concentrations of plasma, insulin and triglycerides in healthy non-diabetic subjects. The non-sugar chocolate had minor effects on the elevation of plasma and insulin concentrations compared to the control chocolate after ingestion. The serum triglycerides were slightly elevated in non-sugar chocolate subjects; however, this parameter was gradually increased in the control subjects. Additionally, an animal study also presented reduced response of serum triglyceride to the administration of a fat emulsion containing polydextrose and lactitol. These observations suggested that the non-sugar chocolate may have a less effect on body fat deposition [81].

\subsubsection{Isomalt}

Over the years the use of isomalt by humans has shown that insulin and blood glucose levels only increase slightly compared to conventional sugar [9,39,82]. The impact of isomalt consumption on physiological and metabolic markers with regards to obesity and diabetes was examined in healthy volunteers. It was reported that consumption of milk chocolate containing $70 \mathrm{~g}$ isomalt resulted in lower postprandial plasma glucose compared to chocolate containing sucrose. Volunteers that had consumed isomalt presented a reduction in glycation products such as frutosamine and glycated haemoglobin (HbA1c) which are associated in delaying the manifestation of diabetes lesions. Therefore, suggesting its possible benefits for diabetes [44]. Holub et al. [83] examined the effect of isomalt in patients with T2D for 12 weeks with $30 \mathrm{~g}$ of isomalt alternatively to higher glycemic carbohydrates. The diet was tolerated with significant reductions in fructosamine, glycated haemoglobin, fasting blood glucose, insulin, C-peptide, proinsulin, insulin resistance (HOMA-IR) and oxidized LDL. It was established that $30 \mathrm{~g}$ isomalt improved the metabolic control of the diabetic patients significantly [83].

\subsubsection{Erythritol}

Erythritol has been reported to contribute no calories and being well tolerated (good digestibility) without any impact on blood glucose and insulin levels. Thus making it appropriate for use in diabetic foods and diets $[46,84]$. Chukwuma et al. [85] examined the effect of erythritol on glucose absorption and glucose uptake in various 
experimental models. Ex vivo, the effect of erythritol was determined by monitoring the glucose concentration change in an incubation containing either isolated rat jejunum or psoas muscle at different concentrations (2.5-20\%) of erythritol. Erythritol presented an increase in glucose uptake in isolated psoas muscle with or without insulin in a dose dependant manner. Insulin significantly improved the effect of erythritol on muscle glucose uptake. In vivo, the effect of an oral dose of erythritol (with phenol red as recovery marker) in normal and T2D rat model was examined on intestinal glucose absorption, gastric emptying and postprandial blood glucose. Erythritol significantly reduced glucose absorption in the first quartile of the small intestine of normal and diabetic animals. It also reduced gastric emptying in diabetic animals, thus preventing a rise in blood glucose [85].

In a previous study, the supplementation of erythritol in doses of 100,200 , or $400 \mathrm{mg}$ ( $\mathrm{kg}$ body weight) ${ }^{-1}$ day $^{-1}$ for ten days in diabetic rats induced with streptozotocin, decreased serum glucose levels significantly with a dose dependant reduction of thio-barbituric acid reactive substances, creatinine and 5-hydroxymethylfurfural in liver, kidney and serum. The study implied that erythritol affects glucose metabolism and reduces lipid peroxidation thus refining oxidative damage involved in the pathogenesis of diabetes [86].

In human studies, Wölnerhanssen et al. [87] investigated the effect of a single bolus dose of $75 \mathrm{~g}$ of erythritol dissolved in $300 \mathrm{~mL}$ water given to lean and obese non-diabetic subjects. The acute ingestion of erythritol led to stimulation of gut hormone release (CCK and GLP-1), with significant delayed gastric emptying. Additionally, insulin and plasma glucose concentrations were not affected [87]. Overduin et al. [88] examined the effect of isovolumic meal with partial replacement of sucrose by erythritol in lean and obese subjects. They found lower glucose and insulin levels after erythritol than after sucrose meals. There was no difference in the secretion of GLP-1/PPY levels, subsequent energy intake and sucrose preference between a control meal with sucrose and isovolumic erythritol meals. It was concluded that the satiating effect of the different preloads were comparable [88].

\subsection{Safety of sugar alcohols}

The Food and Drug Administration (FDA) classifies some polyols as approved food additives. These include erythritol, hydrogenated starch hydrolysates, isomalt, lactitol, maltitol, mannitol, sorbitol, and xylitol $[9,89,90]$. Although, the excessive consumption of polyols causes gastrointestinal symptoms and laxative effects in both humans and animals [13,89,91,92], acceptable daily intake of polyols has been recommended by the Joint FAO/ WHO Expert Committee of Food Additives (JECFA) after extensive toxicological testing [25]. However, in 2017 the European Food Safety Authority called for the safety of polyols used as food additives to be reevaluated. This re-evaluation will be finalized by the end of 2020 [93].

\subsubsection{Xylitol}

Xylitol has been reported to possess numerous positive effects, however, its excessive consumption can affect human health negatively [94]. It has a laxative effect, although the tolerance varies from person to person [13]. It can result in temporary gastrointestinal side effects, such as bloating, flatulence, and diarrhea [66,95]. Akerblom et al. [96] reported that four out of thirteen children experienced transient diarrhea from the consumption of more than 65 g/day xylitol [96]. A study by Wölnerhanssen et al. [87] reported that $50 \mathrm{~g}$ xylitol bolus in $200 \mathrm{~mL}$ water led to bloating and diarrhea in $70 \%$ of all subjects. A review by Mäkinen [66], suggests that the highest safe doses of xylitol ranges from 20 to $70 \mathrm{~g} /$ day. The slow absorption of xylitol from the gut, and the resulting osmotic imbalance, are considered to be the cause of these gastrointestinal side effects, which can be reversed on termination or reduction of the amounts consumed [25].

\subsubsection{Sorbitol}

Sorbitol is generally regarded as safe for use as an additive for human food [25]. However, the excessive ingestion of sorbitol may led to flatulence, abdominal pain and mild to severe diarrhea [13]. The consumption of $20 \mathrm{~g}(0.7 \mathrm{oz}) /$ day of sorbitol as sugar-free gum causes diarrhea resulting to unintentional loss of weight or requiring hospitalization [97]. The addition of sorbitol to sodium polystyrene sulfonate (sps, used in treatment of hyperkalemia) can cause gastrointestinal tract complications, including perforated colonic ulcers, bleeding, ischemic colitis and colonic necrosis [13]. The risk factors for damage induced sorbitol in humans include immune suppression, hypovolemia, peripheral vascular disease, postoperative setting and hypotension [98].

\subsubsection{Mannitol}

Mannitol is the lest well tolerated sugar alcohol with a daily laxative threshold amounting to $20 \mathrm{~g}$ $[14,36]$. The accumulation of maltitol may lead to amplified levels of extracellular fluid which may 
cause asymptomatic heart failure. The intravenous administration of $20 \%$ mannitol can cause electrolyte abnormalities such as hypocalcemia, hypokalemia and hyponatremia $[99,100]$. Hypokalemia may cause nausea, headache, convulsions, vomiting and even coma [100]. It has been reported that an excessive dose of intravenous mannitol can cause acute and persistent nephrotic syndrome [101]. Mannitol worsens cerebral edema when it leaches across the blood-brain barrier, it draws water into instead of out of the brain. This occurs especially in patients with intracranial haemorrhage and children with cerebral hyperemia upon mannitol administration [100]. Mannitol has been suggested to be safe in the elderly and adults at doses ranging from 20 to $100 \mathrm{~g} /$ day, depending on body weight and health status [95].

\subsubsection{Maltitol}

Maltitol is a low digestible carbohydrate, it is not fully metabolized in the small intestine. Therefore, there is concern of over excessive consumption resulting in laxative side effects [102]. Data from literature suggests that $30 \mathrm{~g}$ of maltitol can be ingested as an individual portion in most adults without any laxative effect. The body weight is an important factor regarding the laxative effect of maltitol, a maximum single dose of $0.3 \mathrm{~g} / \mathrm{kg}$ b.w in adults has been reported to have no laxative effect [103]. Koutsou et al. [104] observed that $30 \mathrm{~g}$ maltitol in milk chocolate does not increase digestive discomfort in adults, except for mild flatulence [104]. Maltitol at a higher dose of $40 \mathrm{~g}$ increases colic, borborygmi and flatus, however it does not induce diarrhea [104,105]. Thabuis et al. [106] examined the digestive tolerance of $15 \mathrm{~g} /$ day maltitol in children. The study indicated that maltitol was relatively well tolerated with minor abdominal discomfort [106]. The regular consumption of maltitol is not associated with severe digestive discomfort, diarrhea occurs at much higher doses than those currently consumed [107].

\subsubsection{Lactitol}

Lactitol consumption like most sugar alcohols causes cramping, diarrhea and flatulence in some people, this result due to the deficiency of the enzyme beta-galactosidase in the upper gastrointestinal tract [97]. Lee \& Storey [108] found that consumption of chocolate containing $20 \mathrm{~g}$ of lactitol resulted in bloating, flatulence, colic and borborygmi compared to chocolate containing sucrose in healthy adults. It was also associated with causing diarrhea in the subjects [108]. The laxative effects of lactitol depends on age, person's diet, general gut health and the mode and frequency of digestion $[9,42]$.

\subsubsection{Isomalt}

The ingestion of isomalt in excess is associated with increased colonic fermentation confirming its probability to cause abdominal bloating, flatulence, stomach ache and rumbling noises [109-111]. Subjects ingesting $100 \mathrm{~g}$ milk chocolate containing $40 \mathrm{~g}$ isomalt reported the incidence of colic, flatulence, borborygms, loose stools, motion frequency and mild laxation. However the reduction in isomalt to $30 \mathrm{~g}$ increased tolerance with evidence of mild gastrointestinal side effects [104]. The laxative effect of this sugar alcohol depends on the form in which it is ingested, individual sensitivity, the moment, and frequency of consumption [25].

\subsubsection{Erythritol}

The safety evaluation of erythritol has been thoroughly reviewed, these studies have demonstrated that it is well tolerated $[84,112,113]$. The digestive tolerance study by Tetzloff et al. [114], reported that $1 \mathrm{~g} / \mathrm{kg}$ b.w erythritol consumed over one week can be well tolerated by humans. Storey et al. [115] examined gastrointestinal tolerance after a single oral bolus dose of either $20 \mathrm{~g}, 35 \mathrm{~g}$ or $50 \mathrm{~g}$ of erythritol in seven healthy young adults. Twenty grams and $35 \mathrm{~g}$ erythritol did not trigger any gastrointestinal symptoms, while the highest dose $(50 \mathrm{~g})$ led to an increased number of subjects reporting nausea and borborygmi [115]. Erythritol compared to other sugar alcohols has a lower probability to cause laxative effects. This high laxative threshold enables its use in products such as diet beverages [25]. The consumption of this sugar alcohol from natural sources has been estimated at the level of $106 \mathrm{mg} /$ person/day in Japan, whereas in USA at $25 \mathrm{mg} /$ person/day [116].

\section{Conclusion}

Over the years there has been an escalating interest in the use of polyols as alternative sugars. These compounds look and taste like sugar but are excellent substitutes due to various physical, chemical and biological properties. Numerous studies have shown that polyols have a number of health benefits. Documentation on the glycaemic and insulinemic response of polyols is evident that these compounds have a negligible effect on to postprandial glycemia and insulinemia. Therefore, they are suitable for use by people with diabetes or anyone who wants to live a healthy lifestyle. Continued investigation in diabetic food products is 
still required to ascertain the undiscovered potential of sugar alcohols as alternative sugar substitutes. However, despite these antidiabetic studies there are some possible side effects associated with its usage at normal or higher doses due to the different tolerance ability of different individuals. Thus, future studies should also focus on the possible side effects of different sugar alcohols in humans in order to define their safety.

\section{Conflict of interest}

The authors declare no conflict of interests.

\section{Acknowledgment}

This work was supported by a Competitive Research Grant from the University of KwaZuluNatal, Durban and National Research Foundation (NRF), Pretoria, South Africa.

\section{References}

[1] International Diabetes Federation. IDF diabetes atlas. 9th ed. 2019. Brussels, Belgium.

[2] Bommer C, Sagalova V, Heesemann E, Manne-goehler J, Atun R, Barnighausen T, et al. Global economic burden of diabetes in adults: projections from 2015 to 2030. Diabetes Care 2018;41:963-70. https://doi.org/10.2337/dc17-1962/-/ DC1.S.V.

[3] Zheng Y, Ley SH, Hu FB. Global aetiology and epidemiology of type 2 diabetes mellitus and its complications. Nat Publ Gr 2017;14:88-98. https://doi.org/10.1038/ nrendo.2017.151.

[4] Erickson S, Carr J. The technological challenges of reducing the sugar content of foods. Br Nutr Found Nutr Bull 2020;45: 309-14. https://doi.org/10.1111/nbu.12454.

[5] International Diabetes Federation. IDF framework for action on sugar. 2014. Brussels, Belgium.

[6] Malik VS, Hu FB. Sweeteners and risk of obesity and type 2 diabetes: the role of sugar-sweetened beverages. Curr Diabetes Rev 2012;12:195-203. https://doi.org/10.1007/ s11892-012-0259-6.

[7] Johnston CA, Stevens B, Foreyt JP. Diabetes and nutrition the role of low-calorie sweeteners in diabetes. Diabetres Nutr 2013;9:96-8. https://doi.org/10.17925/EE.2013.09.02.96.

[8] Wolever TMS, Rd AP, Hollands M, Cde RD, Younker K, Rd MBA. Sugar alcohols and diabetes: a review. Canad J Diabetes 2002;26:356-62.

[9] Grembecka M. Sugar alcohols-their role in the modern world of sweeteners: a review. Eur Food Res Tech 2015;241: 1-14. https://doi.org/10.1007/s00217-015-2437-7.

[10] Wölnerhanssen BK, Meyer-Gerspach AC, Beglinger C, Islam S. Metabolic effects of the natural sweeteners xylitol and erythritol: a comprehensive review. Crit Rev Food Sci Nutr 2019;60:1-13. https://doi.org/10.1080/10408398.2019. 1623757.

[11] Gupta M. Sugar substitutes: mechanism, availability, current use and safety concerns-an update. Open Access Maced J Med Sci 2018;6:1888-94. https://doi.org/10.3889/ oamjms.2018.336.

[12] Moon H, Jeya M, Kim I, Lee J. Biotechnological production of erythritol and its applications. Appl Microbiol Biotechnol 2010;86:1017-25. https://doi.org/10.1007/s00253-010-2496-4.
[13] Awuchi CG. Sugar alcoholes: chemistry, production, health concerns and nutritional importance of mannitol, sorbitol, xylitol and erythritol. Int J Adv Acad Res 2017;3:31-66.

[14] Grembecka M. Natural sweeteners in a human diet. Rocziniki Panstw Zakl Hig 2015;66:195-202.

[15] Ibrahim OO. Sugar alcohols: chemical structures, manufacturing, properties and applications. ECronicon Open Access 2019;4:817-24. https://doi.org/10.4172/21559600.C1.026.

[16] Belitz H-D, Grosch W, Schieberle P. Food chemistry. 4th ed. Berlin, Heidelberg: Springer; 2009. https://doi.org/10.1007/ 978-3-540-69934-7.

[17] Rice T, Zannini E, Arendt EK, Coffey A, Rice T, Zannini E, et al. A review of polyols - biotechnological production, food applications, regulation, labeling and health effects. Crit Rev Food Sci Nutr 2020;60:2034-51. https://doi.org/ 10.1080/10408398.2019.1625859.

[18] Kõljalg S, Smidt I, Chakrabarti A, Bosscher D, Mändar R Exploration of singular and synergistic effect of xylitol and erythritol on causative agents of dental caries. Nat Resour J 2020;10:1-7. https://doi.org/10.1038/s41598-020-63153-x.

[19] Mäkinen KK. Sugar alcohol sweeteners as alternatives to sugar with special consideration of xylitol. Med Princ Pract 2011;20:303-20. https://doi.org/10.1159/000324534.

[20] Ur-Rehman S, Mushtaq Z, Zahoor T, Jamil A, Murtaza MA. Xylitol: a review on bioproduction, application, health benefits, and related safety issues. Crit Rev Food Sci Nutr 2015;55:1514-28. https://doi.org/10.1080/10408398.2012. 702288 .

[21] Zacharis C. Xylitol. In: O'Donnell K, Kearsley M, editors. Sweetners sugar altern. Food technol. Second. WILEY; 2012. https://doi.org/10.1002/9781118373941.

[22] Mushtaq Z, Imran M, Salim ur R, Zahoor T, Ahmad RS Arshad MU. Biochemical perspectives of xylitol extracted from indigenous agricultural by-product mung bean (Vigna radiata) hulls in a rat model. J Sci Food Agric 2014;94: 969-74. https://doi.org/10.1002/jsfa.6346.

[23] Barbieri G, Barone C, Bhagat A, Caruso G, Conley ZR, Parisi S. Sweet compounds in foods: sugar alcohols. In: Influ Chem New Foods Tradit Prod. Springer International Publishing; 2014. p. 51-9. https://doi.org/10.1007/978-3-31911358-6.

[24] Fang T, Cai Y, Ogutu CO. Analysis of sorbitol content variation in wild and cultivated apples. J Sci Food Agric 2020;100:139-44. https://doi.org/10.1002/jsfa.10005.

[25] O'Brien Nabors L, editor. Alternative sweeteners. 4th ed. Boca Raton: CRC Press; 2012. https://doi.org/10.1201/ b11242.

[26] Evrendilek GA. Sugar alcohols (polyols). In: Varzakas T, Labropoulos A, Anestis S, editors. Sweeten. nutr. asp. appl. prod. technol. 1st ed. Boca Raton: CRC Press; 2012. https:// doi.org/10.1201/b12065.

[27] Latona DF, Akinola AE. Substrate inhibition: oxidation of D-sorbitol and D-dulcitol by Mn (VII) in alkaline medium. J Chem Biochem 2020;8:8-13. https://doi.org/10.15640/ jcb.v8n1a2.

[28] Silveira M, Jonas R. The biotechnological production of sorbitol. Appl Microbiol Biotechnol 2003;59:400-8. https:// doi.org/10.1007/s00253-002-1046-0.

[29] Ortiz ME, Bleckwedel J, Raya RR, Mozzi F. Biotechnological and in situ food production of polyols by lactic acid bacteria. Appl Microbiol Biotechnol 2013;97:4713-26. https://doi.org/ 10.1007/s00253-013-4884-z.

[30] EFSA. Scientific Opinion on the substantiation of health claims related to the sugar replacers xylitol, sorbitol, mannitol , maltitol , lactitol , isomalt , erythritol , D-tagatose , isomaltulose, sucralose and polydextrose and maintenance of tooth mineralisation by decreasing tooth demineralisation (ID 463, 464, 563, 618, 647, 1182, 1591, 2907, 2921, 4300 ), and reduction of post-prandial glycaemic responses (ID $617,619,669,1590,1762,2903,2908,2920$ ) pursuant to 
Article 13(1) of Regulation (EC) No 1924/2006. EFSA J 2011;9: 2076. https://doi.org/10.2903/j.efsa.2011.2076.

[31] Ruperez P, Toledano G. Celery by-products as a source of mannitol. Eur Food Res Tech 2003;216:224-6. https:// doi.org/10.1007/s00217-003-0663-x.

[32] Jacobsen J, Frigaard N-U. Engineering of photosynthetic mannitol biosynthesis from $\mathrm{CO} 2$ in a cyanobacterium. Metab Eng 2014;21:60-70. https://doi.org/10.1016/ j.ymben.2013.11.004.

[33] Song S, Vieille C. Recent advances in the biological production of mannitol. Appl Microbiol Biotechnol 2009;84: 55-62. https://doi.org/10.1007/s00253-009-2086-5.

[34] Deis R, Kearsley M. Sorbitol and mannitol. In: O'Donnell K, Kearsley MW, editors. Sweeten. sugar altern. food technol. West Sussex UK: Wiley-Blackwell; 2012. p. 331-46. https:// doi.org/10.1002/9781118373941.

[35] Chen M, Zhang W, Wu H. Mannitol: physiological functionalities, determination methods, biotechnological production , and applications. Appl Microbiol Biotechnol 2020; 104:6941-51.

[36] Ghoreishi S, Shahrestani R. Innovative strategies for engineering mannitol production. Trends Food Sci Technol 2009;20:263-70. https://doi.org/10.1016/j.tifs.2009.03.006.

[37] Grembecka M. Sugar alcohols, vol. 0. Elsevier; 2018. https:// doi.org/10.1016/B978-0-08-100596-5.21625-9.

[38] Livesey G. Glycaemic responses and toleration. In: O'Donnell K, Kearsley MW, editors. Sweeten. sugar altern. food technol. West Sussex UK: Wiley-Blackwell; 2012. https://doi.org/10.1002/9781118373941.ch1.

[39] Livesey G. Health potential of polyols as sugar replacers, with emphasis on low glycaemic properties. Nutr Res Rev 2003;16:163-91. https://doi.org/10.1079/NRR200371.

[40] Kearsley MW, Boghani N. Maltitol. In: Nabors Lyn O'Brien, editor. Altern. Sweeten. 4th ed. Boca Raton: CRC Press, Taylor \& Francis Group; 2012. p. 299-314.

[41] Koivistoinen M. Lactitol. In: Wilson R, editor. Sweeteners. 3rd ed. UK: Blackwell Publishing and Leatherhead Publishing; 2007.

[42] Zacharis C. Lactitol. In: O'Donnell K, Kearsley MW, editors. Sweeten. Sugar altern. Food technol. West Sussex UK: Wiley-Blackwell; 2012. https://doi.org/10.1002/ 9781118373941.

[43] Zhang W, Chen J, Chen Q, Wu H, Mu W. Sugar alcohols derived from lactose: lactitol, galactitol, and sorbitol. Appl Microbiol Biotechnol 2020;2. https://doi.org/10.1007/s00253020-10929-w MINI-REVIEW Sugar.

[44] Gostner A, Schaffer V, Theis S, Menzel T, Lu H, Melcher R, et al. Effects of isomalt consumption on gastrointestinal and metabolic parameters in healthy volunteers. Br J Nutr 2005; 94:575-81. https://doi.org/10.1079/BJN20051510.

[45] Sentko A, Willibald-Ettle I. Isomalt. In: O'Donnell K, Kearsley MW, editors. Sweeten. Sugar altern. Food technol. West Sussex UK: Wiley-Blackwell; 2012. https://doi.org/ 10.1002/9781118373941.

[46] De Cock P, Mäkinen K, Honkala E, Saag M, Kennepohl E, Eapen A. Erythritol is more effective than xylitol and sorbitol in managing oral health endpoints. Int J Dent 2016; 2016:1-15. https://doi.org/10.1155/2016/9868421.

[47] Regnat K, Mach RL. Erythritol as sweetener - where from and where to? Appl Microbiol Biotechnol 2018;102:587-95. https://doi.org/10.1007/s00253-017-8654-1.

[48] Rzechonek DA, Dobrowolski A, Rymowicz W, Mirończuk AM, Rzechonek DA, Dobrowolski A, et al. Recent advances in biological production of erythritol. Crit Rev Biotechnol 2018;38:620-33. https://doi.org/10.1080/ 07388551.2017.1380598.

[49] Grembecka M. Sugar alcohols as sugar substitutes in food industry. In: Merillon JM, Ramawat KG, editors. Sweeteners. Springer International Publishing; 2018. p. 547-73. https://doi.org/10.1007/978-3-319-27027-2_23.

[50] Mãkinen KK. Sugar alcohols, caries incidence, and remineralization of caries lesions: a literature review. Int J Dent 2010;2010:1-23. https://doi.org/10.1155/2010/981072.
[51] Kang KW, Kwak SH, Yun SY, Kim SK. Evaluation of antioxidant activity of sugar alcohols using TOSC (total oxyradical scavenging capacity) assay. J Toxicol Public Heal 2007;23:143-50. https://doi.org/10.5487/TR.2007.23.2.143.

[52] Mäkinen KK. Sugar alcohols. In: Goldberg I, editor. Funct. Foods des. Foods, pharmafoods, nutraceuticals. 1st ed. London: Chapman \& Hall; 1994. p. 221-41. https://doi.org/ 10.1007/978-1-4615-2073-3_11.

[53] Schiweck H, Bar A, Vogel R, Schwarz E, Kunz M, Dusautois C, et al. Sugar alcohols. Ullmann's Encycl Ind Chem 2012;1-37. https://doi.org/10.1002/14356007.a25_ 413.pub3.

[54] Grabitske HA, Slavin JL. Gastrointestinal effects of lowdigestible carbohydrates. Crit Rev Food Sci Nutr 2009;49: 327-60. https://doi.org/10.1080/10408390802067126.

[55] Livesey G. The energy values of dietary fibre and sugar alcohols for man. Nutr Metab 1992;5:61-84. https://doi.org/ 10.1079/NRR19920007.

[56] Grabitske HA, Slavin JL. Perspectives in practice lowdigestible carbohydrates in practice. J Am Diatetic Assoc 2008;108:1677-81. https://doi.org/10.1016/j.jada.2008.07.010.

[57] Islam MS. Effects of xylitol as a sugar substitute on diabetes-related parameters in nondiabetic rats. J Med Food 2011;14:505-11. https://doi.org/10.1089/jmf.2010.0015.

[58] Rahman MA, Islam MS. Xylitol improves pancreatic islets morphology to ameliorate type 2 diabetes in rats: a dose response study. J Food Sci 2014;79:1-7. https://doi.org/ 10.1111/1750-3841.12520.

[59] Chukwuma CI, Islam MS. Effects of xylitol on carbohydrate digesting enzymes activity, intestinal glucose absorption and muscle glucose uptake: a multi-mode study. Food Funct 2015;6:955-62. https://doi.org/10.1039/c4fo00994k.

[60] Amo K, Arai H, Uebanso T, Fukaya M, Koganei M, Sasaki $\mathrm{H}$, et al. Effects of xylitol on metabolic parameters and visceral fat accumulation. J Clin Biochem Nutr 2011;49: 1-7. https://doi.org/10.3164/jcbn.10-111.

[61] Chukwuma CI, Islam S. Xylitol improves anti-oxidative defense system in serum, liver,heart, kidney and pancreas of normal and type 2 diabetes model of rats. Acta Pol Pharm 2017;74:817-26.

[62] Yamagata S, Goto Y, Ohneda A, Anzai M, Kawashima S, Shiba M, et al. Clinical effects of xylitol on carbohydrate and lipid metabolism in diabetes. Lancet 1965;2:918-21.

[63] Huttunen JK, Mäkinen KK, Scheinin A. Turku Sugar Studies XI. Effects of sucrose, fructose, and xylitol diets on glucose, lipid and urate metabolism. Acta Odontol Scand 1975;30:239-45.

[64] Mueller-Hess R, Geser CA, Bonjour JP, Jequier E, Felbe JP. Effects of oral xylitol administration on carbohydrate and lipid metabolism in normal subjects. Infusionstherapie 1975;2:247-52. https://doi.org/10.1159/000219627.

[65] Natah SS, Hussien KR, Tuominen JA, Koivisto VA. Metabolic response to lactitol and xylitol in healthy men. Am J Clin Nutr 1997;65:947-50. https://doi.org/10.1093/ajcn/ 65.4.947.

[66] Mäkinen KK. Gastrointestinal disturbances associated with the consumption of sugar alcohols with special consideration of xylitol: scientific review and instructions for dentists and other health-care professionals. Int J Dent 2016;2016: 1-16. https://doi.org/10.1155/2016/5967907.

[67] Foerster H, Boecker S, Walther A. Verwendung von Xylit als Zuckeraustauschstoff bei diabetischen Kindern. Fortschr Med 1977;95:99-102.

[68] Bonner RA, Laine DC, Hoogwerf BJ, Goetz FC. Effects of xylitol, fructose and sucrose in types I and II diabetics: a controlled, cross-over diet study on a clinical research center. Diabetes 1982;31.

[69] Shuman CR, Kemp RG. Clinal use of sorbitol as a sweetening agent in diabetes mellitus. Am J Clin Nutr 1956;4: 61-7. https://doi.org/10.1093/ajcn/4.1.61.

[70] Ellis WF, Krantz JC. Sugar Alcohols XXII. Metabolism and toxicity studies with mannitol and sorbitol in man and animals. J Biol Chem 1941;141:147-54. 
[71] Ellis WF, Krantz JC. Sugar alcohols XXIV. The metabolism of sorbitol in diabetes. Ann Intern Med 1943;18:792-6.

[72] Kang Y-R, Jo S-H, Yoo J-I, Cho J-B, Kim E-J, Apostolidis E, et al. Anti-hyperglycemic effect of selected sugar alcohols (829.32). Faseb J 2014;28:829-32. https://doi.org/10.1096/ fasebj.28.1_supplement.829.32.

[73] Chukwuma CI, Islam S. Sorbitol increases muscle glucose uptake ex vivo and inhibits intestinal glucose absorption ex vivo and in normal and type 2 diabetic rats. Appl Physiol Nutr Metabol 2017;42:377-83. https://doi.org/10.1139/ apnm-2016-0433.

[74] Mãkinen KK, Hamalainen MM. Metabolie effects in rats of high oral doses of galactitol, mannitol and xylitol. J Nutr 1985;115:890-9. https://doi.org/10.1093/jn/115.7.890.

[75] Dillard CJ, Kunert K, Tappel A. Effects of vitamin E , ascorbic acid and mannitol on alloxan-induced lipid peroxidation in rats. Arch Biochem Biophys 1982;216:204-12. https://doi.org/10.1016/0003-9861(82)90205-3.

[76] Chukwuma CI, Ibrahim MA, Islam MS. Maltitol inhibits small intestinal glucose absorption and increases insulin mediated muscle glucose uptake ex vivo but not in normal and type 2 diabetic rats. Int J Food Sci Nutr 2017;68:73-81. https://doi.org/10.1080/09637486.2016.1216527.

[77] Secchi A, Pontiroli A, Cammelli L, Bizzi A, Cini M, Pozza G. Effects of oral administration of maltitol on plasma glucose, plasma sorbitol, and serum insulin levels in man. Weiner Klin Wocgenschrift 1986;64:265-9. https://doi.org/10.1007/ BF01711933.

[78] Moon S, Lee M, Huh K, Lee K. Effects of maltitol on blood glucose and insulin responses in normal and diabetic subjects. Korean J Nutr 1990;23:270-8.

[79] Vessby B, Karlstrom B, Skarfors E. Comparison of the effects of maltitol with those of sucrose, fructose and sorbitol on blood glucose and serum insulin concentrations in healthy and non-insulin dependent diabetic subjects: studies after an oral load and after addition to a standard breakfast meal. Diabetes Nutr Metabol Clin Exp 1990;3: 231-7.

[80] Quilez J, Bullo M, Salas-Savado J. Improved postprandial response and feeling of satiety after consumption of low-calorie muffins with maltitol and high-amylose. J Food Sci 2007;72:407-11. https://doi.org/10.1111/j.1750-3841.2007. 00408.x.

[81] Shimomura $Y$, Maeda $K$, Nagasaki M, Matsuo $Y$, Murakami T, Bajotto G, et al. Attenuated response of the serum triglyceride concentration to ingestion of a chocolate containing polydextrose and lactitol in place of sugar. Biosci Biotechnol Biochem 2005;69:1819-23. https://doi.org/ 10.1271/bbb.69.1819.

[82] Thiébaud D, Jacot E, Schmitz H, Spengler M, Felber JP. Comparative study of isomalt and sucrose by means of continuous indirect calorimetry. Metabolism 1984;33: 808-13. https://doi.org/10.1016/0026-0495(84)90106-9.

[83] Holub I, Gostner A, Hessdorfer S, Theis S, Bender G, Willinger B, et al. Improved metabolic control after 12-week dietary intervention with low glycaemic isomalt in patients with type 2 diabetes mellitus. Horm Metab Res 2009;41: 886-92. https://doi.org/10.1055/s-0029-1234107.

[84] Bornet FRJ, Blayo A, Dauchy F, Slama G. Gastrointestinal response and plasma and urine determinations in human subjects given erythritol. Regul Toxicol Pharmacol 1996;24: 296-302. https://doi.org/10.1006/rtph.1996.0111.

[85] Chukwuma CI, Mopuri R, Nagiah S, Chuturgoon AA, Islam MS. Erythritol reduces small intestinal glucose absorption, increases muscle glucose uptake, improves glucose metabolic enzymes activities and increases expression of Glut- 4 and IRS-1 in type 2 diabetic rats. Eur J Nutr 2018;57:2341-4. https://doi.org/10.1007/s00394-0171516-x.

[86] Yokozawa T, Kim HY, Cho EJ. Erythritol attenuates the diabetic oxidative stress through modulating glucose metabolism and lipid peroxidation in streptozotocin- induced diabetic rats. J Agric Food Chem 2002;50:5485-9. https://doi.org/10.1021/jf020168z.

[87] Wölnerhanssen BK, Cajacob L, Keller N, Doody A, Rehfeld JF, Drewe J, et al. Gut hormone secretion, gastric emptying, and glycemic responses to erythritol and xylitol in lean and obese subjects. Am J Physiol Endocrinol Metab 2016;310:1053-61. https://doi.org/10.1152/ajpendo.00037. 2016.

[88] Overduin J, Collet T, Medic N, Henning E, Keogh JM, Forsyth F, et al. Failure of sucrose replacement with the non-nutritive sweetener erythritol to alter GLP-1 or PYY release or test meal size in lean or obese people. Appetite 2016;107:596-603. https://doi.org/10.1016/j.appet.2016.09. 009.

[89] Ruiz-Ojeda FJ, Plaza-Díaz J, Sáez-Lara MJ, Gil A. Effects of sweeteners on the gut microbiota: a review of experimental studies and clinical trials. Adv Nutr 2019;10:S31-48. https:// doi.org/10.1093/advances/nmy037.

[90] Food Standards Agency. Current EU approved additives and their E numbers. 2016. https://www.food.gov.uk/ science/additives/enumberlist\#toc-4. [Accessed 19 October 2020].

[91] Dills WLJ. Sugar alcohols as bulk sweeteners. Annu Rev Nutr 1989;9:161-86.

[92] Lenhart A, Chey WD. A systematic review of the effects of polyols on gastrointestinal health and irritable bowel syndrome. Adv Nutr 2017;8:587-96. https://doi.org/10.3945/ an.117.015560.

[93] European Food Safety Authority. Call for technical and toxicological data on sweeteners authorised as food additives in the EU. 2017. https://www.efsa.europa.eu/en/data/ call/170621. [Accessed 19 October 2020].

[94] Gasmi Benahmed A, Gasmi A, Arshad M, Shanaida M, Lysiuk R, Peana M, et al. Health benefits of xylitol. Appl Microbiol Biotechnol 2020;104:7225-37. https://doi.org/ 10.1007/s00253-020-10708-7.

[95] Antonik N, Janda K, Jakubczyk K. Characteristics of sweeteners used in foods and their effects on human health. Pomeranian J Life Sci 2020;66:57-65. https://doi.org/ 10.21164/pomjlifesci.723.

[96] Akerblom HK, Koivukangas T, Puukka R, Mononen M. The tolerance of increasing amounts of dietary xylitol in children. Int J Vitam Nutr Res Suppl = Int Zeitschrift Fur Vitamin- Und Ernahrungsforschung Suppl 1982;22:53-66.

[97] Awuci CG, Echeta KC. Current developments in sugar alcohols: chemistry, nutrition, and health concerns of sorbitol, xylitol, glycerol, arabitol, inositol, maltitol, and lactitol. Int J Adv Acad Res 2019;5:2488-9849.

[98] Erfani M, Akula Y, Zolfaghari T, Hertan HI. Sodium polystyrene sulfonate (SPS): sorbitol-induced colonic necrosis. Practical Gastroenterol 2010;34:47-50.

[99] Rossi1 S, Picetti1 E, Zoerle T, Carbonara M, Zanier ER, Stocchetti N. Fluid management in acute brain injury. Curr Neurol Neurosci Rep 2018;18:1-9. https://doi.org/10.1007/ s11910-018-0885-8.

[100] Tenny S, Patel R, Thorell W. Mannitol. Treasure Isl.: StatPearls Publishing; 2018.

[101] Nissenson AR, Weston RE, Kleeman CR, Angeles L. Mannitol. West J Med 1979;131:277-84.

[102] Livesey G. Tolerance of low-digestible carbohydrates: a general view. Br J Nutr 2001;85:7-16. https://doi.org/ 10.1079/bjin2000257.

[103] Kearsley MW, Boghani N. Maltitol. 2016. p. 299-314. https://doi.org/10.1201/b11242-21.

[104] Koutsou GA, Storey DM, Lee A, Zumbe A, Flourie B, LeBot $Y$, et al. Dose-related gastrointestinal response to the ingestion of either isomalt, lactitol or maltitol in milk chocolate. Eur J Clin Nutr 1996;50:17-21.

[105] Storey DM, Koutsou GA, Lee A, Zumbe A, Olivier P, Bot Y Le, et al. Tolerance and breath hydrogen excretion following ingestion of maltitol incorporated at two levels into milk chocolate consumed by healthy young adults with 
and without fasting. J Nutr 1998;128:587-92. https://doi.org/ 10.1093/jn/128.3.587.

[106] Thabuis C, Cazaubiel M, Pichelin M, Wils D, GuerinDeremaux L. Short-term digestive tolerance of chocolate formulated with maltitol in children. Int J Food Sci Nutr 2010;61:728-38. https://doi.org/10.3109/ 09637481003766812.

[107] Ruskoné-Fourmestraux A, Attar A, Chassard D, Coffin B, Bornet $\mathrm{F}$, Bouhnik Y. A digestive tolerance study of maltitol after occasional and regular consumption in healthy humans. Eur J Clin Nutr 2003;57:26-30. https://doi.org/ 10.1038/sj.ejcn.1601516.

[108] Lee A, Storey DM. Comparative gastrointestinal tolerance of sucrose, lactitol, or D-tagatose in chocolate. Regul Toxicol Pharmacol 1999;29:78-82. https://doi.org/10.1006/ rtph.1998.1255.

[109] Lee A, Storey D, Zumbe A. Breath hydrogen after ingestion of the bulk sweeteners sorbitol, isomalt and sucrose in chocolate. Br J Nutr 1994;71:731-7. https://doi.org/10.1079/ BJN19940180.

[110] Zumbe A, Brinkworth R. Comparative studies of gastrointestinal tolerance and acceptability of milk chocolate containing either sucrose, isomalt or sorbitol in healthy consumers and type II diabetics. Z Ernahrungswiss 1992;31: 40-8. https://doi.org/10.1007/BF01612551.

[111] Spengler M, Somoygi J, Pletcher E, Boehme K. Tolerability, acceptance and energetic conversion of isomalt (Palatinit) in comparison with sucrose. Aktuelle Ernährungsmed 1987;12: $210-4$.

[112] Ishikawa $M$, Miyashita $M$, Kawashima $Y$, Nakamura $T$, Saitou N, Modderman J. Effects of oral administration of erythritol on patients with diabetes. Regul Toxicol Pharmacol 1996;24:303-8.

[113] Bornet FRJ, Blayo A, Dauchy F, Slama G. Plasma and urine kinetics of erythritol after oral ingestion by healthy humans. Regul Toxicol Pharmacol 1996;24:280-5.

[114] Tetzloff W, Dauchy F, Medimagh S, Carr D, Bar A. Tolerance to subchronic, high-dose ingestion of erythritol in human volunteer. Regul Toxicol Pharmacol 1996;24:286-95.

[115] Storey D, Lee A, Bornet F, Brouns F. Gastrointestinal tolerance of erythritol and xylitol ingested in a liquid. Eur J Clin Nutr 2007;61:349-54. https://doi.org/10.1038/ sj.ejcn.1602532.

[116] de Cock P. Erythritol. In: O'Donnell K, Kearsley M, editors. Sweeten. Sugar altern. Food technol. West Sussex UK: Wiley-Blackwell; 2012. 